[Technical Paper]

\title{
Unloaded Quality Factor for Hairpin Resonator Affected by Conduction and Radiation Losses on K-band
}

\author{
Satoshi Ono and Koji Wada \\ The University of Electro-Communications, 1-5-1, Chofugaoka, Chofu-shi, Tokyo 182-8585, Japan
}

(Received August 3, 2018; accepted December 3, 2018, published December 21, 2018)

\begin{abstract}
We investigate the effects of an Electroless Nickel Immersion Gold (ENIG) layer, the roughness of mat face on copper foil, and the radiation loss along a microstrip line and input/output coaxial connectors. The surface finishing process for planar circuits using a printed circuit board (PCB) is very important for preventing the corrosion of copper foil. There is a problem with coating the surface of copper foil because the conduction losses caused by the materials for surface finishing are higher than that of low-frequency bands. In addition, the roughness of the mat face on copper foil strongly affects the losses of the circuits at high frequencies. Moreover, radiation losses by coaxial connectors or some bonding methods like wire-bonding are a problem. In this paper, we distinguish some causes of losses in a hairpin resonator and a two-pole band-pass filter (BPF) by developing some theoretical equations and electromagnetic simulation models. Also, this verification is applied to the measured results of two-pole BPF. The effects of ENIG, copper roughness and radiation between coaxial connectors and a microstrip line on unloaded quality factor $\left(Q_{0}\right)$ of the hairpin resonator are quantitatively revealed.
\end{abstract}

Keywords: Electrodeless Nickel Immersion Gold (ENIG), Roughness of Copper Foil, Hairpin Resonator, Conduction Quality Factor $\left(Q_{c}\right)$, Dielectric Quality Factor $\left(Q_{d}\right)$, Radiation Quality Factor $\left(Q_{r}\right)$, Unloaded Quality Factor $\left(Q_{0}\right)$, Band-pass Filter (BPF), Polytetrafluoroethylene (PTFE) Substrate

\section{Introduction}

Fifth-generation (5G) service for wireless communication will begin in 2020 . The operating frequency from the K-band (18-26 GHz) to the Ku-band $(26-40 \mathrm{GHz})$ will be the target frequency band.[1] Circuits using printed circuit boards (PCB) are more important for radio frequency (RF) circuits, baseband circuits, and many other circuits in $5 \mathrm{G}$ service. When these circuits are used in severe environments, pure copper foil is corroded by oxidization and moisture in atmosphere. Therefore, surface finishes on the pattern of copper foil are necessary to prevent the oxidation. Table 1 shows some kinds of surface finishes. [2, 3] Shelf time means shelf life. Also, the Relative Cost Adder in Table 1 defines the cost factor of only surface finishing. [2] If this cost factor is higher, the production cost is higher. Generally, the hot air solder process with $\mathrm{Sn} / \mathrm{Pb}$ solder or $\mathrm{Pb}$-free solder is a popular process because of its good solderability and low-cost process. However, in the case of circuits on a higher frequency, the electrical characteristics will be worse, since the flatness of the layers of
$\mathrm{Sn} / \mathrm{Pb}$ solder or $\mathrm{Pb}$-free solder is coarse. Here, we focus on the process of Electroless Nickel Immersion Gold (ENIG) because of its flat surface, good solderability, long shelf time, and relatively lower product cost. The ENIG process is an electroless plating process. In a general process, the thicknesses of Ni-P and flash gold layers are about $3 \mu \mathrm{m}$ and less than $50 \mathrm{~nm}$, respectively.[3]

Yoshitomi[4] showed the relative conductivity in the case of Ni/Au layers of a microstrip line composed of Polytetrafluoroethylene (PTFE) substrate made by Arlon, Inc. They showed the relative conductivity affected by $\mathrm{Ni} /$ $\mathrm{Au}$ layers at $20 \mathrm{GHz}$ is less than $30 \%$ compared with pure copper foil. That means there is no candidate for PCB passivation beyond the K-band possessing low surface resistance. In addition, the roughness of the mat face on copper foil is caused by high transmission loss beyond the K-band. The mat face of copper foil refers to the boundary between the copper foil and the dielectric material. Generally, the roughness of electrodeposited (ED) copper foil is equal to $1.8 \mu \mathrm{m}$, which is 4.5 times the skin depth at $20 \mathrm{GHz}$.[5] 
Table 1 Characteristics of surface finishes.

\begin{tabular}{c|c|c|c|c}
\hline Material & Types of surface finishings & Thickness $(\mu \mathrm{m})$ & $\begin{array}{c}\text { shelf time } \\
\text { (month) }\end{array}$ & $\begin{array}{c}\text { Relative } \\
\text { Cost Adder }\end{array}$ \\
\hline $\begin{array}{c}\text { Benzotriazole-system, } \\
\text { Imidazole-system (Organic) }\end{array}$ & $\begin{array}{c}\text { Organic Solderability } \\
\text { Preservative }\end{array}$ & 0.01 to 0.4 & about 6 & 1.0 \\
\hline $\mathrm{Sn} / \mathrm{Pb}$ & Hot Air Soder Level & 0.762 to 38.1 & 12 & 1.0 \\
\hline $\mathrm{Pb} \mathrm{Free} \mathrm{solder}$ & Hot Air Soder Level & 0.762 to 38.1 & 12 & 1.0 \\
\hline $\mathrm{Ag}$ & Immersion Silver & 0.203 to 0.381 & 6 to 12 & 1.1 \\
\hline $\mathrm{Sn}$ & Immersion Tin & 0.203 to 0.381 & 6 & 1.1 \\
\hline $\mathrm{Ni} / \mathrm{Au}$ & Electrolytic Ni/Au & $\begin{array}{c}0.127 \text { to } 0.381 \\
(\mathrm{Gold} \text { Flash) }\end{array}$ & 12 & 3.5 \\
\hline $\mathrm{Ni} / \mathrm{P} / \mathrm{Pd} / \mathrm{Au}$ & $\begin{array}{c}\text { Electroless Nickel } \\
\text { Electroless Palladium } \\
\text { Immersion Gold (ENEPIG) }\end{array}$ & $\begin{array}{c}\text { Ni-P: } 3.05 \text { to } 6.09, \\
\text { Pd: } 0.101 \text { to } 0.508, \\
\text { Au: } 0.05 \text { to } 0.203\end{array}$ & 12 & 2.5 \\
\hline $\mathrm{Ni} / \mathrm{Au}$ & $\begin{array}{c}\text { Electroless Nickel } \\
\text { Immersion Gold (ENIG) }\end{array}$ & $\begin{array}{c}\text { Ni-P: } 3.05 \text { to } 6.09, \\
\text { Au: } 0.05 \text { to } 0.203\end{array}$ & 12 & 1.1 \\
\hline
\end{tabular}

Radiation losses by patterned input/output feed lines and some coaxial connectors are also a problem. Moreover, it is necessary to reduce radiation losses through resonator shape in a band-pass filter (BPF). A hairpin resonator on the K-band has many positive features, including a compact structure and lower radiation loss than with a halfwave straight-type resonator. It is possible to reduce the radiation loss on the $\mathrm{K}$-band for a hairpin resonator to about one tenth compared with that of a half-wave straighttype resonator by optimizing the thickness of the substrate and the size of the line and space of the hairpin resonator. Therefore, hairpin resonators are used for various highfrequency filters. These losses are related to an attenuation constant $\alpha$, which is a real part of the propagation constant for $\gamma$ and used for discussing the performance of transmission lines. Unloaded factor $Q_{0}$ is inversely proportional to $\alpha$ and a very important factor for determining the loss performances of various high-frequency filters. That means filters using resonators with a high $Q_{0}$ produce low insertion loss and high performance.

In this paper, firstly, conduction quality factor $Q_{c}$, dielectric quality factor $Q_{d}$, radiation quality factor $Q_{r}$, and $Q_{0}$ for the hairpin resonator are defined using equations. $Q_{c}$ and $Q_{d}$ are quality factors based on conductor loss and dielectric loss, respectively. $Q_{r}$ is also a quality factor based on radiation loss caused from the shapes of a circuit pattern and the boundary structure between the circuit pattern and coaxial connector, and so on. Secondly, two-pole BPF at $20 \mathrm{GHz}$ using hairpin resonators is configured and fabricated for investigating the effects of ENIG, the surface roughness on copper foil, and radiation by input/output feed lines and some coaxial connectors. Although it is common sense that conduction and radiation losses are degraded by those factors, there is no paper which quantitatively analyzed them using theoretical equations, electromagnetic (EM) simulation and measurement. Finally, the effects of ENIG, copper roughness and radiation between coaxial connectors and the microstrip line on the $Q_{0}$ of the resonator are quantitatively revealed.

\section{Theoretical Verification of $Q_{c}, Q_{d}, Q_{r}$ and $Q_{0}$ for Hairpin Resonator}

$2.1 Q_{c}, Q_{d}, Q_{r}$ and $Q_{0}$ in case of pure copper foil with the surface roughness of zero thickness

The structure of a hairpin resonator was discussed in [6]. Figure 1 shows an electromagnetic (EM) simulation model for verification of theoretical $Q_{0}$. The dimensions of a hairpin resonator for calculations of $Q_{c}, Q_{d}, Q_{r}$ and $Q_{0}$ using some equations are the same as those shown in Fig. 1. Also, the substrate for the hairpin resonator is assumed to be Polytetrafluoroethylene (PTFE) substrate, whose dielectric constant, $\tan \delta$ and PTFE substrate thickness are 2.2, 0.0007 and $0.254 \mathrm{~mm}$, respectively. Moreover, the conductivity and thickness of the copper foil on substrate are $5.8 \times 10^{7} \mathrm{~S} / \mathrm{m}$ and $18 \mu \mathrm{m}$. The respective equations for $Q_{c}$, $Q_{d}, Q_{r}, Q_{0}$ and $\alpha$ are as follows:[7]

$$
Q_{c}=10.965 \frac{Z_{c}^{a} h(m m)}{R_{s, r} A} \sqrt{f(G H z)}
$$




$$
\begin{aligned}
& Q_{d}=\frac{\varepsilon_{r}^{\prime}+1+\left(\varepsilon_{r}^{\prime}-1\right)\left(1+\frac{10 h}{W}\right)^{-0.5}}{\varepsilon_{r}^{\prime} \tan _{\varepsilon}\left\{1+\left(1+\frac{10 h}{W}\right)^{-0.5}\right\}} \\
& Q_{r}=2 \pi \frac{P_{\text {in }}}{P_{\text {rad }}}=\frac{Z_{C}}{2 \sqrt{\frac{\mu_{0}}{\varepsilon_{0}}} F_{1,2}\left(\frac{h}{\lambda_{0}}\right)^{2}} \\
& Q_{0}=\frac{1}{\left(\frac{1}{Q_{c}}+\frac{1}{Q_{d}}+\frac{1}{Q_{r}}\right)} \\
& \alpha_{x}=\frac{\beta}{2 Q_{x}}=8.686 \frac{\pi \sqrt{\varepsilon_{e f f}}}{Q_{x} \lambda_{0}}(d B / m)(\mathrm{x}=\mathrm{c}, \mathrm{d}, \mathrm{r} \text { and } 0) \\
& \alpha_{0}=\alpha_{c}+\alpha_{d}+\alpha_{r} \\
& \varepsilon_{\text {eff }}=\frac{\varepsilon_{r}^{\prime}+1}{2}+\frac{\varepsilon_{r}^{\prime}+1}{2}\left(1+\frac{10 h}{W}\right)^{-\frac{1}{2}}-\frac{\varepsilon_{r}^{\prime}-1}{4.6} \frac{t / h}{\sqrt{W / h}}
\end{aligned}
$$

Table 2 shows the parameters for Eqs. (1) - (7). $Q_{r}$ is predicted by the results of [8] because $P_{i n} / P_{\text {rad }}$ in the equation of $Q_{r}$ is difficult to theoretically define. The values of $Q_{c}, Q_{d}, Q_{r}, Q_{0}, \alpha_{c}, \alpha_{d}, \alpha_{r}$ and $\alpha_{0}$ for a surface roughness of zero on copper foil are shown in Table 3 . The $\varepsilon_{\text {eff }}$ for calculating $\alpha_{x}(\mathrm{x}=\mathrm{c}, \mathrm{d}, \mathrm{r}$ and 0$)$ is equal to 1.87 , which is determined using Eq. (7). The calculated $Q_{0}$ from Eq. (4) for the hairpin resonator is 245 . Also, the ratio of attenuation constants by conductor, dielectric material and radiation are

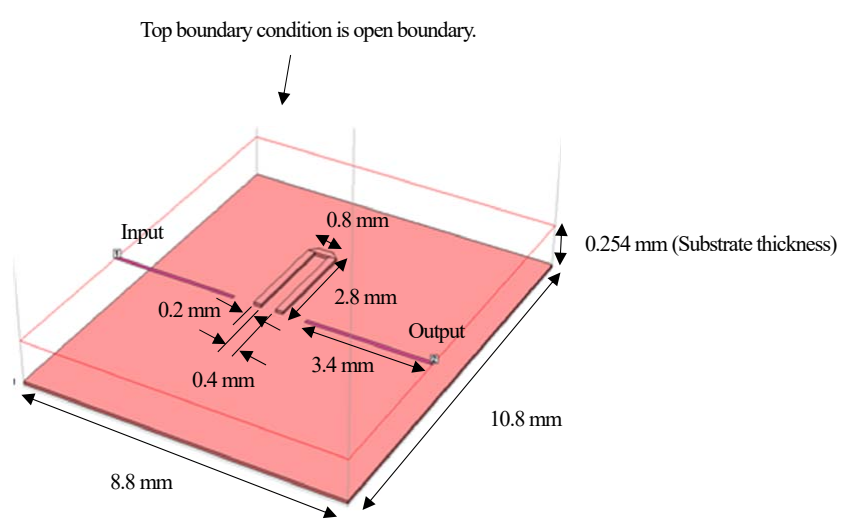

Fig. 1 EM simulation model for calculating $Q_{0}$. shown in Table 3 . It was found that the conductor loss of the hairpin resonator at $20 \mathrm{GHz}$ is most dominant.

The calculated theoretical $Q_{0}$ using EM simulation will need to be verified. Sonnet ver. 15. 52 is used for EM simulation of Fig. 1. The conductor and dielectric models for EM simulation are assumed to be copper and PTFE substrate, respectively. The conductivity and thickness of copper are $5.8 \times 10^{7} \mathrm{~S} / \mathrm{m}$ and $18 \mu \mathrm{m}$. Also, the thick metal

\begin{tabular}{|c|c|}
\hline Parameters & Description \\
\hline$Z_{a}{ }^{C}$ & $\begin{array}{l}\text { Characteristic impedance in the case of air } \\
\text { medium. }\end{array}$ \\
\hline$h$ & Thickness of dielectric substrate \\
\hline$f$ & Frequency \\
\hline$R_{s, r}$ & Normalized resistance by copper \\
\hline$A$ & Theoretical conductor attenuation factor[11] \\
\hline$\varepsilon_{r}^{\prime}$ & Real part of dielectric constant for substrate \\
\hline$W$ & Line width of copper on top side of substrate \\
\hline $\tan \delta \varepsilon$ & Dielectric tangent for substrate \\
\hline$P_{\text {in }}$ & Input power \\
\hline$P_{\text {rad }}$ & Radiation power \\
\hline$Z_{c}$ & $\begin{array}{l}\text { Characteristic impedance in the case of dielec- } \\
\text { tric medium }\end{array}$ \\
\hline$\mu_{0}$ & Permeability in air \\
\hline$\varepsilon_{0}$ & Permittivity in air \\
\hline$F_{1,2}$ & Radiation factor \\
\hline$\lambda_{0}$ & Wavelength in air \\
\hline$\beta$ & Phase constant for transmission line \\
\hline$\varepsilon_{\text {eff }}$ & Effective dielectric constant \\
\hline$\alpha_{c}$ & Attenuation constant caused by conduction loss \\
\hline$\alpha_{d}$ & Attenuation constant caused by dielectric loss \\
\hline$\alpha_{r}$ & Attenuation constant caused by radiation loss \\
\hline$\alpha_{0}$ & Attenuation constant caused by total loss \\
\hline
\end{tabular}
model (TMM) for two sheets is used as the conductor model. TMM means a conductor model which is able to consider physically thick planar metal.[9] The simulated results of conduction loss for two sheets are accurate

Table 2 Parameters of Equations (1) to (7).

Table $3 Q_{c}, Q_{d}, Q_{r}, Q_{0}, \alpha_{c}, \alpha_{d}, \alpha_{r}$ and $\alpha_{0}$ for zero surface roughness of copper foil.

\begin{tabular}{l|c|c|c|c}
\hline & $Q_{c}$ & $Q_{d}$ & $Q_{r}$ & $Q_{0}$ \\
\hline \multirow{4}{*}{$\begin{array}{l}\text { Zero surface roughness copper foil } \\
\text { (Theoretical values) }\end{array}$} & 388 & 1,802 & 1,053 & 245 \\
\cline { 2 - 5 } & $\alpha_{c}(\mathrm{~dB} / \mathrm{m})$ & $\alpha_{d}(\mathrm{~dB} / \mathrm{m})$ & $\alpha_{r}(\mathrm{~dB} / \mathrm{m})$ & $\alpha_{0}(\mathrm{~dB} / \mathrm{m})$ \\
\cline { 2 - 5 } & 6.2 & 1.3 & 2.3 & 9.9 \\
\cline { 2 - 5 } & $\left(\alpha_{c} / \alpha_{0}\right) \times 100(\%)$ & $\left(\alpha_{d} / \alpha_{0}\right) \times 100(\%)$ & $\left(\alpha_{r} / \alpha_{0}\right) \times 100(\%)$ & \\
\cline { 2 - 5 } & 63.2 & 13.6 & 23.2 & \\
\hline
\end{tabular}


Table $4 Q_{c}, Q_{d}, Q_{r}$ and $Q_{0}$ for zero surface roughness of copper foil by EM simulation.

\begin{tabular}{l|c|c|c|c}
\hline & $Q_{c}$ & $Q_{d}$ & $Q_{r}$ & $Q_{0}$ \\
\hline \multirow{4}{*}{$\begin{array}{l}\text { Zero surface roughness copper foil } \\
\text { (EM Simulation) }\end{array}$} & 264 & 2,000 & 1,020 & 190 \\
\cline { 2 - 5 } & $\alpha_{c}(\mathrm{~dB} / \mathrm{m})$ & $\alpha_{d}(\mathrm{~dB} / \mathrm{m})$ & $\alpha_{r}(\mathrm{~dB} / \mathrm{m})$ & $\alpha_{0}(\mathrm{~dB} / \mathrm{m})$ \\
\cline { 2 - 5 } & 9.5 & 1.3 & 2.5 & 13.3 \\
\cline { 2 - 5 } & $\left(\alpha_{c} / \alpha_{0}\right) \times 100(\%)$ & $\left(\alpha_{d} / \alpha_{0}\right) \times 100(\%)$ & $\left(\alpha_{r} / \alpha_{0}\right) \times 100(\%)$ & \\
\cline { 2 - 5 } & 71.4 & 9.8 & 18.8 & \\
\hline
\end{tabular}

Table $5 Q_{c}, Q_{d}, Q_{r}$ and $Q_{0}$ for surface roughness on mat face of $1.8 \mu \mathrm{m}$ (RMS).

\begin{tabular}{l|c|c|c|c}
\hline & $Q_{c}$ & $Q_{d}$ & $Q_{r}$ & $Q_{0}$ \\
\hline \multirow{4}{*}{$\begin{array}{l}\text { Mat face roughness of } 1.8 \mu \mathrm{m}(\mathrm{RMS}) \\
\text { (Theoretical values) }\end{array}$} & 197 & 1,802 & 1,053 & 152 \\
\cline { 2 - 5 } & $\alpha_{c}(\mathrm{~dB} / \mathrm{m})$ & $\alpha_{d}(\mathrm{~dB} / \mathrm{m})$ & $\alpha_{r}(\mathrm{~dB} / \mathrm{m})$ & $\alpha_{0}(\mathrm{~dB} / \mathrm{m})$ \\
\cline { 2 - 5 } & 12.3 & 1.3 & 2.3 & 15.9 \\
\cline { 2 - 5 } & $\left(\alpha_{c} / \alpha_{0}\right) \times 100(\%)$ & $\left(\alpha_{d} / \alpha_{0}\right) \times 100(\%)$ & $\left(\alpha_{r} / \alpha_{0}\right) \times 100(\%)$ & \\
\cline { 2 - 5 } & 77.2 & 8.4 & 14.4 & \\
\hline
\end{tabular}

excluding the case of very tightly coupling between coupled lines below the conductor thickness. [9] The dielectric constant, $\tan \delta$ and thickness of PTFE substrate are 2.2, 0.0007 and $0.254 \mathrm{~mm}$. Table 4 shows the calculated $Q_{0}$ and $\alpha$ from the frequency characteristics by Sonnet. The effective dielectric constant for calculating $\alpha_{x}(\mathrm{x}=\mathrm{c}, \mathrm{d}, \mathrm{r}$ and 0$)$ is 1.91 at $20 \mathrm{GHz}$, which was calculated by Sonnet. The difference of $Q_{0}$ between the theoretical values (Table 3 ) and electromagnetic simulation is about $22.5 \%$. These results show that theoretical verification is good for estimating $Q_{c}$, $Q_{d}, Q_{r}$ and $Q_{o}$ in advance of EM simulation. It is an especially useful method for approximate design, since verification using theoretical equations is faster, simpler and more flexible. The effects of a rough surface copper foil and ENIG will be verified using this method.

\section{$2.2 Q_{c}, Q_{d}, Q_{r}$ and $Q_{0}$ in the case of pure copper} foil considering the roughness of the mat face

The roughness on the mat face of copper foil for a PTFE substrate is $1.8 \mu \mathrm{m}$ in the case of electrodeposited (ED) copper foil [5]. Figure 2 shows a cross-section of PCB with ED copper foil. The mat face of the copper foil indicates the boundary between the copper foil and dielectric material while the other side indicates a shiny face. There are many kinds of models for the rough surface of a conductor, for example, the Morgan, Hammerstad and Jensen (NHJ) model,[10, 11] the snowball model,[12] and so on. In this study, the MHJ model is used for modeling the mat face. The key feature of the MHJ model is that it is simple and basic for conductor roughness. The electrical influence of conductor roughness can be considered by calcu-

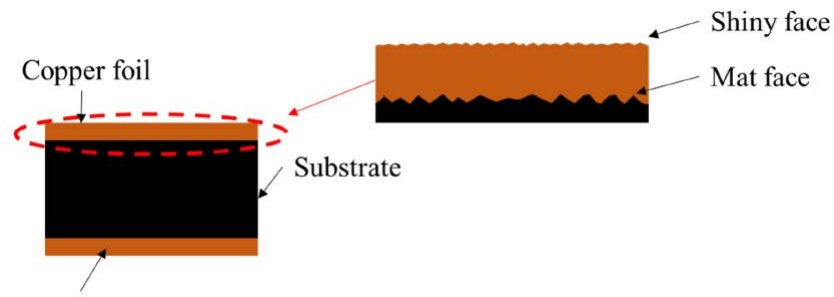

Copper foil

Fig. 2 Cross-section of PCB with ED copper foil.

lating the attenuation constant using the values of the root mean square (RMS) of conductor roughness and skin depth for the operating frequency. Although another model is probably more accurate than the MHJ model, it is needed for the detailed shape and dimensions of the boundary between the conductor and the dielectric material of the PCB using Scanning Electron Microscopy (SEM) or Transmission Electron Microscopy (TEM). The equation for the attenuation constant with the MHJ model is as follows:

$$
\alpha_{\text {rough }}(\Delta)=\alpha_{\text {smooth }}\left[1+\frac{2}{\pi} \arctan \left\{1.4\left(\frac{\Delta}{\delta}\right)^{2}\right\}\right] .
$$

$\alpha_{\text {rough }}(\Delta)$ shows the attenuation constant considering roughness of $\Delta$, which is the RMS of the conductor roughness. $\alpha_{\text {smooth }}$ and $\delta$ show the attenuation constant in the case of zero roughness and skin depth for metal at the operating frequency, respectively. The values of $Q_{c}, Q_{d}, Q_{r}$ and $Q_{0}$ for $\Delta$ on the mat face of $1.8 \mu \mathrm{m}$ are shown in Table 5 . Also, the ratios of the attenuation constants by conductor, dielectric material and radiation are shown in Table 5. 
Table $6 \quad \alpha_{c_{-} C u}$ and $\alpha_{c_{-} E N I G}$ for references [4], [18] and [19].

\begin{tabular}{l|c|c|c}
\hline \multicolumn{1}{c|}{ Author } & $\alpha_{c_{-} C u}(\mathrm{~dB} / \mathrm{m})$ & $\alpha_{c_{-} E N I G}(\mathrm{~dB} / \mathrm{m})$ & $\alpha_{\mathrm{c}_{-} \mathrm{ENIG}} / \alpha_{\mathrm{c}_{-} \mathrm{Cu}}$ \\
\hline Yoshitomi [4] & 31 & 36 & 1.16 \\
\hline Coonrod [18] & 21 & 26 & 1.24 \\
\hline Huber [19] & $36 @ 25 \mathrm{~mm}$ & $44 @ 25 \mathrm{~mm}$ & 1.22 \\
\hline
\end{tabular}

Table $7 Q_{c}, Q_{d}, Q_{r}$ and $Q_{0}$ for ENIG on surface roughness on mat face of $1.8 \mu \mathrm{m}$.

\begin{tabular}{l|c|c|c|c}
\hline & $Q_{c}$ & $Q_{d}$ & $Q_{r}$ & $Q_{0}$ \\
\hline \multirow{4}{*}{$\begin{array}{l}\text { ENIG / rough copper foil } \\
\text { in the case of } 1.8 \mu \mathrm{m} \\
\text { (Theoretical values) }\end{array}$} & 164 & 1,802 & 1,053 & 132 \\
\cline { 2 - 5 } & $\alpha_{c}(\mathrm{~dB} / \mathrm{m})$ & $\alpha_{d}(\mathrm{~dB} / \mathrm{m})$ & $\alpha_{r}(\mathrm{~dB} / \mathrm{m})$ & $\alpha_{0}(\mathrm{~dB} / \mathrm{m})$ \\
\cline { 2 - 5 } & 14.7 & 1.3 & 2.3 & 18.4 \\
\cline { 2 - 5 } & $\left(\alpha_{c} / \alpha_{0}\right) \times 100(\%)$ & $\left(\alpha_{d} / \alpha_{0}\right) \times 100(\%)$ & $\left(\alpha_{r} / \alpha_{0}\right) \times 100(\%)$ & \\
\hline
\end{tabular}

The $Q_{c}$ is almost half of the value compared with that of zero roughness (Table 3 ) because $\alpha_{c}$ is degraded until about twice at $20 \mathrm{GHz}$ in the case of $1.8 \mu \mathrm{m}$ roughness. The $Q_{0}$ in the case of considering the mat face roughness is $62 \%$ compared with that of zero roughness.

\section{3 $Q_{c}, Q_{d}, Q_{r}$ and $Q_{o}$ in the case of ENIG/rough mat face of copper foil}

Staiculescu[13] showed the synthesized attenuation constant and surface resistance for Nickel and Copper foil. This method is effective for calculating the attenuation constant with $\mathrm{Ni} / \mathrm{Au}$ layers. Also, Deng[14] and Curran[15] have defined the effective skin depth, propagation constant and characteristic impedance for a multilayer coated conductor. However, it is difficult to determine the parameters of conductivity and magnetic permeability because the physical parameters of Ni-P alloy for high frequencies depend on the measurement method and operating frequency.[16-18] Therefore, the effects of ENIG are predicted from the measured results in previous research. Table 6 shows the attenuation constants for only copper foil $\left(\alpha_{c_{-} C u}\right)$ and ENIG $\left(\alpha_{c_{-} E N I G}\right)$ which were extracted by the measured or calculated transmission characteristics in three papers. [4, 18, 19] These results show the ratio of $\alpha_{c_{-} C u}$ and $\alpha_{c_{-} E N I G}$ is almost in agreement, which is about 1.2. The $\Delta$ of the mat face of copper foil is equal to $1.8 \mu \mathrm{m}$ in Table 7 . When $Q_{c}$ and $Q_{0}$ are calculated from the extracted ratio of $\alpha_{c_{-} C u}$ and $\alpha_{c_{-} E N I G}, Q_{c}$ and $Q_{0}$ are equal to 164 and 132, respectively. In Ref.,[20] there is a case in which the measured insertion losses at $20 \mathrm{GHz}$ by copper and ENIG have an inverse relationship with the general cases. There is a possibility to degrade performance by oxidation of pure copper. If this is compared with the inser-
Table 8 Design specification of two-pole BPF.

\begin{tabular}{l|c}
\hline Center frequency of $f_{0}(\mathrm{GHz})$ & 20 \\
\hline Passband bandwidth of $B W(\mathrm{GHz})$ & 1 \\
\hline Fractional bandwidth of $F B W(\%)$ & 5 \\
\hline Passband ripple $(\mathrm{dB})$ & 0.022 \\
\hline Minimum return loss in passband $(\mathrm{dB})$ & 22.97 \\
\hline Insertion loss of $I L(\mathrm{~dB})$ & 1.65 \\
\hline
\end{tabular}

tion losses by EM simulation for pure copper and measurement for ENIG, the ratio of them is about 1.02. Also, Ref. [21] shows RF resistances by five kinds of surface finish process. The ratio of the calculated power at $20 \mathrm{GHz}$ of copper and ENIG are around 1.33. Therefore, the calculated $Q_{c}$ and $Q_{0}$ are reasonable since it is almost agreement with this verification.

\section{Design of Two-pole BPF}

The design specification of two-pole BPF is shown in Table 8. The dielectric substrate is assumed to be PTFE substrate, whose dielectric constant and $\tan \delta$ are equal to 2.2 and 0.0007 , respectively. Figure 3 shows the calculated characteristic functions using $g$-parameters for Chebyshevtype two-pole BPF based on the design specifications of Table 8. The design specification of $I L$ is determined based on $Q_{0}$, which is equal to 132 . Conductivity for the ENIG conductor model in Sonnet is determined by EM simulation results for only a hairpin resonator. This value is not only the physical parameter but also the fitting parameter. Although the dielectric model for electromagnetic simulation is similar to that of section 2 , the conductivity and thickness of the conductor model is determined to $4.0 \times$ 


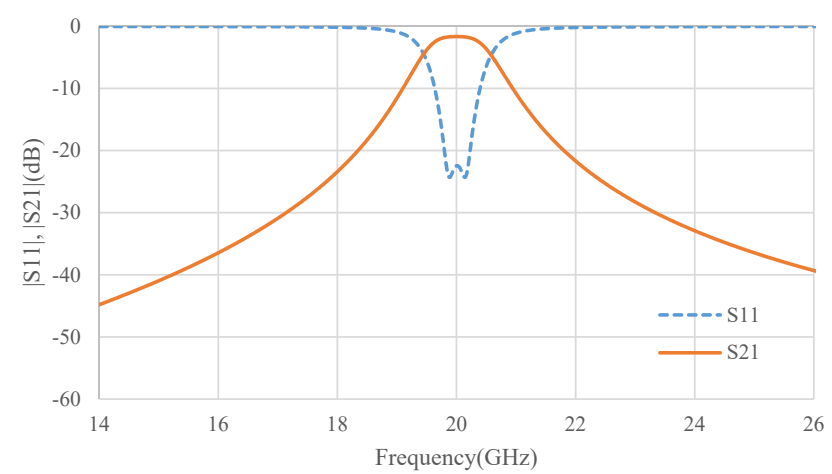

Fig. 3 Calculated frequency characteristics for Chebyshevtype two-pole BPF by design specification.

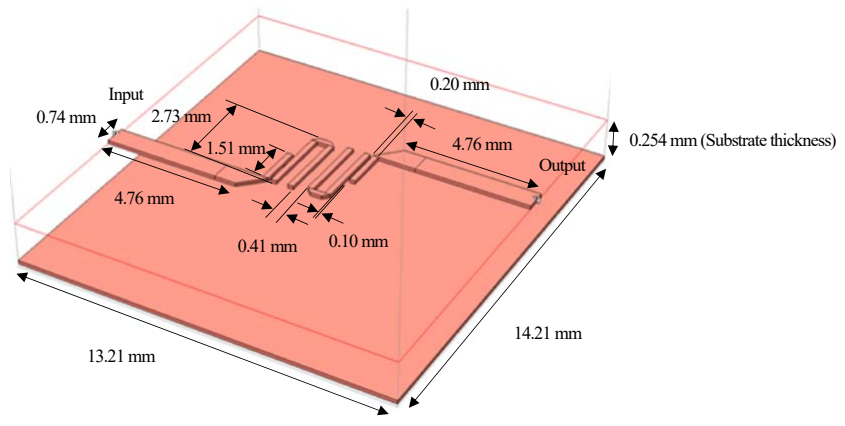

Fig. 4 The layout of two-pole BPF.

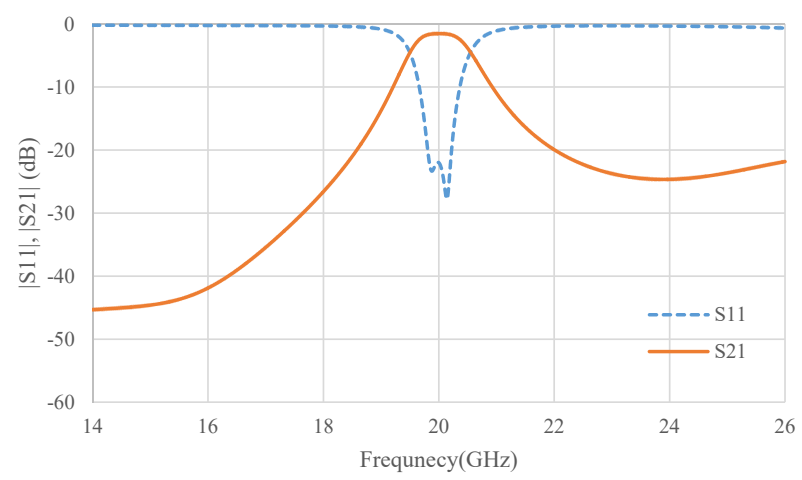

Fig. 5 The simulation results of Fig. 4.

$10^{7} \mathrm{~S} / \mathrm{m}$ and $21.05 \mu \mathrm{m}$. The configured structure of twopole $\mathrm{BPF}$ using a conventional design procedure of $\mathrm{BPF}$ and Sonnet is shown in Fig. 4. Figure 5 also shows the simulated results of the presented BPF. It is almost in agreement with the frequency characteristics of Fig. 3.

\section{Fabrication and Measurement of Two-pole BPF}

\subsection{Fabrication and measurement of two-pole BPF} using hairpin resonators

An image of fabricated two-pole BPF is shown in Fig. 6. It is fabricated by a commercial wet etching process. Figure 7 shows the compared results with EM simulation and measurement for two-pole BPF. Table 9 shows the main

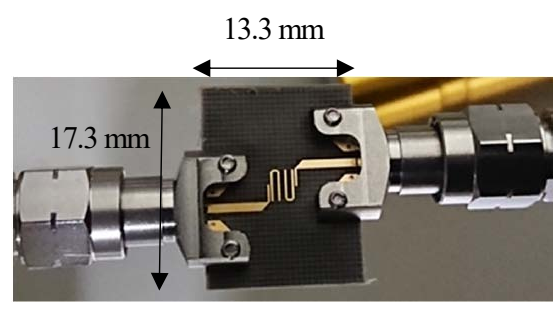

Fig. 6 Image of fabricated two-pole BPF.

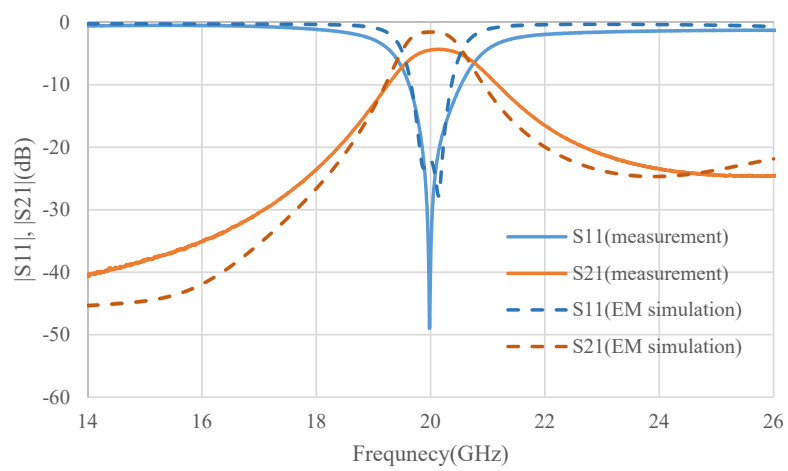

Fig. 7 Comparison with EM simulation and measurement for two-pole BPF.

Table 9 Measured results for two-pole BPF.

\begin{tabular}{c|c|c}
\hline Parameters & simulation & Measurement \\
\hline$f_{0}(\mathrm{GHz})$ & 19.99 & 20.2 \\
\hline$B W(\mathrm{GHz})$ & 1.054 & 1.28 \\
\hline$F B W(\%)$ & 5.27 & 6.34 \\
\hline$I L(\mathrm{~dB})$ & 1.54 & 3.85 \\
\hline
\end{tabular}

parameters for EM simulation and measurement for twopole BPF. The measured results are acquired by an E8364B vector network analyzer (VNA). The VNA is calibrated using mechanical SOLT kits before measurement. 2.4-mm coaxial connectors are used as the interface of the VNA and two-pole BPF. The $I L$ for measured results is higher than that for EM simulation. When $Q_{0}$ is estimated by $I L$ for measured results, it is equal to 42.65 .

4.2 Effects of conductor and radiation losses for input/output feed lines and radiation loss for 2.4 mm connectors

Figure 8 shows the compared results in the cases of deembedding or not de-embedding the effects of input/output feed lines and input/output coaxial connectors. When the effects of input/output feed lines and coaxial connectors are removed using the method by Tomita,[22] IL by de-embedding input/output feed lines is $1.31 \mathrm{~dB}$ lower than that of the not de-embedding one. Firstly, the effects of input/output feed lines are excluded by de-embedding them. Secondly, scattering parameters transform to a two- 
port short-circuit admittance matrix. Finally, that is transformed to a coupling matrix, which is expressed by resonant frequencies, coupling coefficients, external quality factors of BPF and unloaded quality factors of resonators. [22] It is a very effective extraction method. Higher insertion loss means that conduction losses by $2.4-\mathrm{mm}$ connectors and input/output feed lines and radiation losses among 2.4-mm connectors and input/output feed lines are equal to $1.31 \mathrm{~dB}$. The average $Q_{0}$ of two-pole BPF after removing those effects is equal to 60.68 . This value is not in agreement with $Q_{0}$ (it is equal to 42.65 .) calculated by the $I L$ of two-pole BPF. It is considered that those causes occur because of radiation along the microstrip lines and 2.4-mm connectors. The relationship of $P_{\text {rad }} / P_{\text {in }}$ for radiation along the microstrip lines and coaxial connector is shown in.[7,23] $P_{\text {rad }}$ and $P_{i n}$ show the radiation and input power, respectively. The equations for $Q_{r}$ are defined as follows:

$$
\begin{gathered}
Q_{r_{-24 \text { Ann }} \text { connector }}=2 \pi \frac{P_{\text {in }}}{P_{\text {rad }}}=2 \pi \frac{9}{4 Z_{C}}\left\{\frac{\lambda_{0} h}{\left(r_{b}-r_{a}\right) r_{a}}\right\}^{2} \\
=\pi \frac{9 \lambda_{0}^{2} h^{2}}{2 Z_{c}\left\{\left(r_{b}-r_{a}\right) r_{a}\right\}^{2}} \\
Q_{r_{-} \text {total }}=\frac{1}{\frac{1}{Q_{r_{-24 \text { Anm }} \text { connector }}}+\frac{1}{Q_{r_{-244 m m} \text { connector }}}+\frac{1}{Q_{r_{-} B P F}}},
\end{gathered}
$$

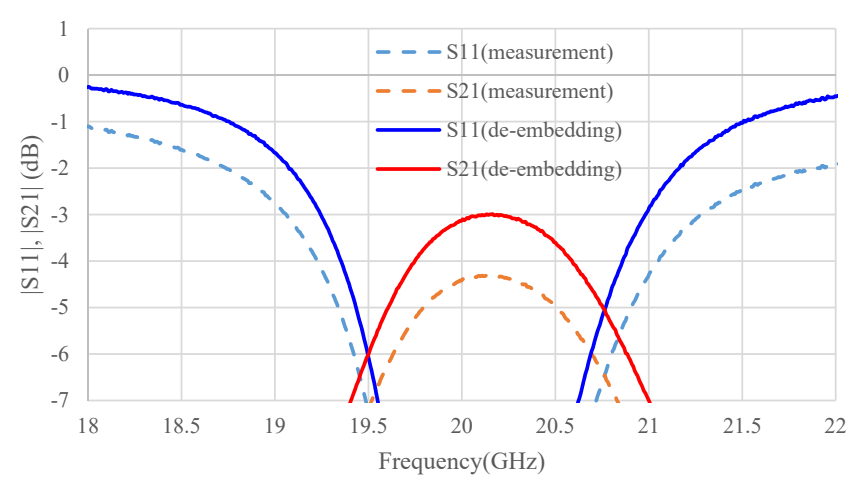

Fig. 8 Compared results in cases of de-embedding or not deembedding the effects of input/output feed lines and coaxial connectors. where $r_{a}$ and $r_{b}$ indicate the inner and outer radii of the coaxial connector, respectively. The other parameters are the same as Table 2. In Eq. (10), $Q_{r_{-B P F}}$ indicates the radiation quality factor $Q_{r}$ in Table 7 , which is equal to 1,053 . When $Q_{r_{-} \text {total }}$ is calculated using Eqs. (9) and (10), it is equal to 62.63. Equation (4) indicates that the additive law of reciprocal each quality factor is established. Therefore, Eq. (10) is also established even if the causes of $Q_{r}$ in the BPF are complicated. There are two reciprocal terms of $Q_{r \_2.4 m m}$ connector in Eq. (10) since two 2.4-mm connectors are used in two-pole BPF. $Q_{c}, Q_{d}, Q_{r_{-} \text {total }}$ and $Q_{0}$ for ENIG on copper with 1.8- $\mu \mathrm{m}$ roughness on the mat face adds the effects of radiation from two 2.4-mm connectors are shown in Table 10. Also, Table 10 shows the ratio of $\alpha_{c}, \alpha_{d}$ and $\alpha_{r_{-} \text {total }}$ in the case of considering radiation losses among input/output feed lines and 2.4-mm connectors. There is almost agreement with $Q_{0}$ estimated by $I L$ for the measured results of two-pole BPF. It was found that the effect of radiation between a microstrip line and a coaxial connector is not neglected when the coaxial connector is used as the interface of the planar circuit.

Finally, Fig. 9 shows the bar graph of $\alpha_{c}, \alpha_{d}, \alpha_{r}$ and $\alpha_{0}$ in each condition shown in Tables $3,5,7$ and 10 , respectively. It was found that the roughness on the mat face strongly

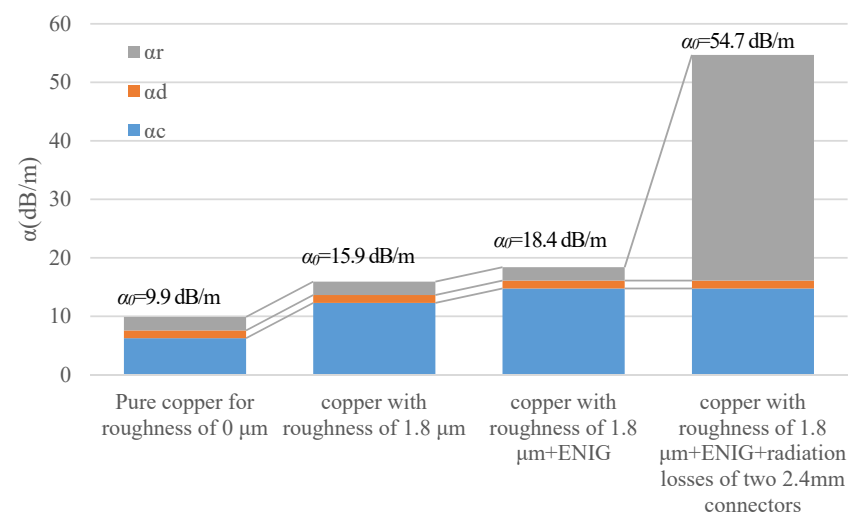

Fig. 9 Comparison of $\alpha_{c}, \alpha_{d}, \alpha_{r}$ and $\alpha_{0}$ in each condition shown in Tables 3, 5, 7 and 10.

Table $10 Q_{c}, Q_{d}, Q_{r_{-} \text {total }}$ and $Q_{0}$ for ENIG on copper with $1.8-\mu \mathrm{m}$ roughness on mat face adding the effects of radiation from two 2.4-mm connectors.

\begin{tabular}{l|c|c|c|c}
\hline & $Q_{c}$ & $Q_{d}$ & $Q_{r_{-} \text {total }}$ & $Q_{0}$ \\
\hline \multirow{3}{*}{$\begin{array}{l}\text { ENIG / rough copper foil } \\
\text { in the case of } 1.8 \mu \mathrm{m}\end{array}$} & 164 & 1,802 & 63 & 44 \\
\cline { 2 - 5 } $\begin{array}{l}\text { adding the effects of radiation } \\
\text { from two } 2.4 \text { mm connectors } \\
\text { (Theoretical values) }\end{array}$ & $\alpha_{c}(\mathrm{~dB} / \mathrm{m})$ & $\alpha_{d}(\mathrm{~dB} / \mathrm{m})$ & $\alpha_{r_{-} \text {total }}(\mathrm{dB} / \mathrm{m})$ & $\alpha_{0}(\mathrm{~dB} / \mathrm{m})$ \\
\cline { 2 - 5 } & 14.7 & 1.3 & 38.6 & 54.7 \\
\cline { 2 - 5 } & $\left(\alpha_{c} / \alpha_{0}\right) \times 100(\%)$ & $\left(\alpha_{d} / \alpha_{0}\right) \times 100(\%)$ & $\left(\alpha_{r} / \alpha_{0}\right) \times 100(\%)$ & \\
\cline { 2 - 5 } & 26.9 & 2.5 & 70.6 & \\
\hline
\end{tabular}


affected $Q_{c}$. Although it is better to use rolled copper foil, its known tensile strength is weaker than that of ED copper foil. Recently, some kinds of ED copper foils which are relatively lower loss, strong tensile strength and low cost have been realized.[24] It is important to select a PCB considering cost and performance. The improvement of $Q_{c}$ affected by ENIG is very difficult if only using the standard process for ENIG. If raising the product cost is allowed, it is very effective to optimize the thickness of gold and Ni-P alloy layers or change the material for the bonding metal. The radiation between a microstrip line and a coaxial connector should be suppressed for improvement of $Q_{r}$. For instance, using electromagnetic shields around coaxial connectors has been considered. Although it is effective using a ground-signal-ground (GSG) probe for measurement, using coaxial connectors is inevitable if discrete BPF is needed for system design at the level of a $\mathrm{RF}$ frontend system. Therefore, it is important to improve the structure to include an electromagnetic shield and coaxial connectors without the occurrence of unwanted resonances by TE or TM modes.

\section{Conclusion}

We quantitatively investigated the effects of an Electroless Nickel Immersion Gold (ENIG) layer, the roughness of mat face on copper foil, and the radiation loss along a microstrip line and coaxial connectors using some theoretical equations, EM simulation and measured results. The verified results using some equations were almost in agreement with $Q_{0}$ estimated by $I L$ for the measured results of two-pole $\mathrm{BPF}$ using hairpin resonators. It is shown that those results are effective for BPF design on the K-band. In future work, the accuracy of the theoretical values will be raised and suppression methods for the effects of conduction and radiation losses will be proposed.

\section{Acknowledgements}

We would like to deeply thank to Dr. Norimasa Ishitobi (Sonnet Software, Inc.) and Dr. Ryo Ishikawa (The University of Electro-Communications) for their contributions.

\section{References}

[1] AWG-20/TMP-63, "WORKING DOCUMENT FOR NEW APT REPORT ON SHARING AND COMPATIBILITY STUDIES FOR IMT ABOVE $24 \mathrm{GHz}$," The 20th Meeting of the APT Wireless Group (AWG-20), September, 2016.

[2] T. Henniger, "PCB Surface Finishes," https://www.
smta.org/chapters/files/UMW_Viasystems_ Surface_Finishes.pdf, browsed on July 31, 2018.

[3] T. Sasabe, M. Akiyama, K. Kato, K. Kozu, and M. Ishii, “[Japanese] Zitsumu ni yakunitatsu Purinto haisenban no mekki gijyutsu [Really useful practice for plating technology for printed circuit board]," pp. 103-110, Japan Industrial Publishing Co., Ltd., 2012, ISBN 978-4-526-06814-0 C3054.

[4] R. Yoshitomi, Y. Kobayashi, and Z. Ma, “[Japanese] Precise Estimation of Propagation Constants of a Microstrip Line Based on Material Constants Measured for Copper-Clad Laminate Substrate,” Journal of The Japan Institute of Electronics Packaging, Vol. 14, No. 2, pp. 114-120, 2011.

[5] Technical paper of Rogers Corporation, "Copper Foil for High Frequency Materials,” https://www. rogerscorp.com/documents/749/acs/Copper-Foilsfor-High-Frequency-Circuit-Materials.pdf, browsed on July 31.

[6] S. Ono and K. Wada, "Fundamentals and Vital Points of Planar Filter in the Case of Higher Frequency," Microwave Workshops and Exhibition (MWE 2017), WE3B-2, pp. 45-54, 2017.

[7] Y. Konishi, “[Japanese] Zitsuyou maikuroha gijyutsu kouza -Riron to zissai- dai 1 kan [Practical microwave technology course -Theory and practice - No. 1],” pp. 119-159 and pp. 195-196, K-Laboratory, 2001, ISBN 978-4-798-7971-2.

[8] R. J. Roberts and B. Easter, "Microstrip Resonators Having Reduced Radiation Loss," Electronics Letters, 22nd, Vol. 7, No. 8, pp. 191-192, 1971.

[9] Sonnet Software, Inc., “SONNET USER'S GUIDE Release 15,” Rev. 15.52, pp. 293-304, 2014.

[10] S. P. Morgan Jr., "Effect of Surface Roughness on Eddy Current Losses at Microwave," Journal of Applied Physics, Vol. 20, pp. 352-362, 1949.

[11] E. O. Hammerstad and O. Jensen, "Accurate Models for Microstrip Computer Aided Design,” IEEE MTT-S int. Microwave Symposium Digest, pp. 407409, 1980.

[12] P. G. Huray, O. Oluwafemi, J. Loyer, E. Bogatin, and X. Ye, "Impact of Copper Surface Texture on Loss: A Model that Works,” DesignCon 2010, pp. 462-483, 2010.

[13] D. Staiculescu, J. Laskar, J. Mendelsohn, E. Sweetman, D. Rudy, and I. Artaki, "Ni-Au Surface Finish Effects on RF Performance," IEEE MTT-S International Microwave Symposium Digest, Vol. 4, 
pp. 1909-1912, 1999.

[14] H.-W. Deng, Y.-J. Zhao, C.-J. Liang, W.-S. Jiang, and Y.-M. Ning, "Effective Skin Depth for Multilayer Coated Conductor,” Progress In Electromagnetics Research M, Vol. 9, pp. 1-8, 2009.

[15] B. Curran, G. Fotheringham, C. Tschoban, I. Ndip, and K.-D. Lang, "On the Modeling, Characterization, and Analysis of the Current Distribution in PCB Transmission Lines With Surface Finishes," IEEE Transactions on Microwave Theory and Techniques, Vol. 64, No. 8, pp. 2511-2518, 2016.

[16] Y. Tao and F. H. Scharf, "Revisiting the Effect of Nickel Characteristics on High-Speed Interconnect Performance," IEEE Transactions on Microwave Theory and Techniques, Vol. 64, No. 8, pp. 24472453, Aug. 2016.

[17] S. Lucyszyn, "Microwave Characterization of Nickel,” PIER ONLINE, Vol. 4, No. 6, pp. 686-690, 2008.

[18] J. Coonrod, "Ambiguous Influences Affecting Insertion Loss of Microwave Printed Circuit Boards," IEEE microwave magazine, Vol. 13, Issue 5, pp. 66-75, 2012.

[19] O. Huber, T. Faseth, H. Arthaber, and E. Schlaffer, "Optimized Launching Pads for Investigating Transmission Line Losses for Different Surface Finishes of RF-PCBs up to $110 \mathrm{GHz}$," IEEE MTT-S International Microwave and RF Conference (IMaRC), pp. 165168, 2015.

[20] O. Huber, G. Magerl, and H. Arthaber, "Impact of Different Surface Finishes on Insertion Loss for Microstrip Resonators up to $110 \mathrm{GHz}$," IEEE Radio and Antenna Days of the Indian Ocean (RADIO), pp. $1-2,2017$.

[21] B. Curran, I. Ndip, and K.-D. Lang, "A Comparison of Typical Surface Finishes on the High Frequency Performances of Transmission Lines in PCBs," IEEE 21st Workshop on Signal and Power Integrity (SPI), 2017.

[22] R. Tomita, M. Ohira, Z. Ma, and X. Wang, "An Improved Coupling-Matrix Extraction Method of Microwave Bandpass Filters with De-embedding
Technique for Transmission Loss of Input/Output Lines," The IEICE Transactions on Electronics (Japanese Edition), Vol. J100-C, No. 12, pp. 569-579, 2017.

[23] A. Henderson and J. R. James, "Design of microstrip antenna feeds. Part 1: Estimation of radiation loss and design implications," IEEE Proceedings H Microwaves, Optics and Antennas, Vol. 128, Issue 1, pp. 19-25, 1981.

[24] Copper Foil Products list by FURUKAWA ELECTRIC Co., LTD., https://www.furukawa.co.jp/foil/en/ products/index.html, browsed on July 31.

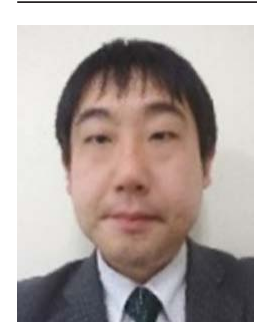

Satoshi Ono received his Doctorate from Yamagata University, Yamagata, Japan, in 2010. From 2010 to 2016, he was an Engineer with the Corporate Manufacturing Engineering Center, Toshiba Corporation, Kanagawa, Japan. Since 2016, he has worked as an Assistant Professor at the Department of Communication Engineering and Informatics in the Graduate School of Informatics and Engineering at the University of Electro-Communications, Tokyo, Japan. His research interests include resonators, filters and multiplexers. Dr. Ono is a member of the Institute of Electronics, Information and Communication Engineers (IEICE) and The Japan Society of Applied Physics (JSAP).

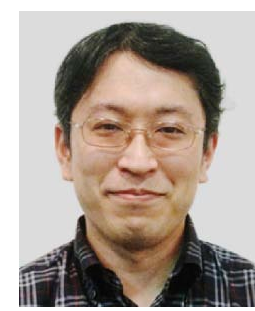

Koji Wada received his Doctorate from Yamaguchi University, Yamaguchi, Japan, in 1999. From 1999 to 2004, he was a Research Associate with the Department of Electrical Engineering and Electronics at Aoyama Gakuin University, Kanagawa, Japan. From 2004 to 2015, he worked as an Associate Professor at the Department of Electronic Engineering at the University of Electro-Communications, Tokyo, Japan and he is currently a Professor in the Department of Communication Engineering and Informatics in the Graduate School of Informatics and Engineering at the University of Electro-Communications. His research interests include resonators, filters, multiplexers, multiband circuits, tunable circuits, periodic structure, and metamaterial circuits. Dr. Wada is a member of the Institute of Electronics, Information and Communication Engineers (IEICE) and the Institute of Electrical Engineers of Japan (IEEJ). 